\title{
Primary characterization of micro holes on super alloy by percussion of millisecond pulse laser
}

\author{
Jiahong Wang ${ }^{2,1, a^{*}}$, Yang Sheng ${ }^{1, b}$,Guohao Cheng ${ }^{3, c}$, Qiang Zhu ${ }^{4, d}$, Yunlong \\ Wang $^{5, e^{*}}$
}

${ }^{1}$ School of Materials Science and Engineering, Jiangsu University, Zhenjiang, 212013,China

${ }^{2}$ Zhenjiang technician college, Zhenjiang, 212013,China

${ }^{3}$ School of Materials Science and Engineering, Jiangsu University, Zhenjiang, 212013,China

aWangjiahong@ujs.edu.cn (Co-corresponding author Email), bshengyang@sina.cn, 'Chenggh@ujs.edu.cn ${ }^{\mathrm{d}}$ Zhqng@163.com, ${ }^{\mathrm{d}}$ wyl306wm@ujs.edu.cn (Co-corresponding author Email)

Keywords: Laser drilling, micro hole, millisecond pulse laser, percussion, super alloy

\begin{abstract}
Micro holes were formed on GH4169 super alloy using a millisecond pulse Nd:YAG laser with a average power of $65 \mathrm{~J}$ and positive defocus of $3 \mathrm{~mm}$ from the sample surface. The microstructure of the micro hole including morphology and elements composition were analyzed using Scanning Electron microscopy (SEM), and Energy Dispersive X-ray Spectrometer (EDS) .The results indicate that the diameter of holes is about $330 \mu \mathrm{m}$ with relatively high roundness. The elements composition of the area near the hole surface are different. It shows gradually increasing of $\mathrm{O}$ element content and decreasing of Fe element content from the substrate to the area near the hole surface.
\end{abstract}

\section{Introduction}

Recently, laser drilling has gained increasing attention due to the rapid of development of some industries such as aerospace and automobile industries, and the application of laser drilling process has been widely extended[1-2]. Laser drilling is a non-contact process that can be used to form micro holes in a wide variety of materials with a high precision and efficiency. Many aircraft engine components including combustion chambers, nozzle guide vanes, casings and turbine blades, are all subjected to lase drilling[3-5]. Many researches in literatures have focused on the drilling process of short or ultra-short pulse laser, including both experimental characterization and theorical modeling[6-8]. However, laser drilling using long pulse, especially millisecond pulse laser was seldom studied, which shows high efficiency and high importance in industry application. The present paper deal with the characterization of micro holes on super alloy obtained by percussion of millisecond pulse laser. The microstructure of the micro hole including morphology and elements composition were primarily studied.

\section{Experimental details}

\section{Drilling of micro holes}

The tests was carried out using a pulsed Nd:YAG laser (LASAG FLS 352A, DEMAG, German) which is equipped on with a five-axis machine tool (power LT80, DEMAG, German). The output wavelength of laser is $1064 \mathrm{~nm}$; the pulse duration can range from $0.1-3 \mathrm{~ms}$; the pulse frequency is $0.1-500 \mathrm{~Hz}$; the maximum energy is $50 \mathrm{~J}$ with the maximum mean power of $170 \mathrm{w}$. The diameter of the nozzle is $6 \mathrm{~mm}$ and the laser focus is $3 \mathrm{~mm}$ below.

The drilling test was performed on a pie shaped GH4169 super alloy with the thickness of $1 \mathrm{~mm}$ and the radius of $15 \mathrm{~mm}$, whose chemical composition was listed in table 1.During drilling process, the distance between two micro holes was kept $2 \mathrm{~mm}$, so that the holes would not affect each other. 
The primary parameters were adopted, namely $30 \mathrm{~Hz}, 1000 \mu \mathrm{s}, 4000$ beam expanding, minus defocus $3 \mathrm{~mm}$ and 0.4 bar oxygen as auxiliary gas and the average power was $65 \mathrm{w}$.

Table 1. Chemical composition of GH4169 super alloy

\begin{tabular}{ccccccccccccc}
\hline \multirow{2}{*}{ Element } & $\mathrm{C}$ & $\mathrm{Cr}$ & $\mathrm{Ni}$ & $\mathrm{Mo}$ & $\mathrm{Ti}$ & $\mathrm{Mn}$ & $\mathrm{Al}$ & $\mathrm{Si}$ & $\mathrm{P}$ & $\mathrm{S}$ & $\mathrm{Nb}$ & $\mathrm{Fe}$ \\
\hline \multirow{2}{*}{ Content } & $\leqslant$ & 17 & 50.0 & 2.8 & 0.65 & $\leqslant$ & 0.2 & $\leqslant$ & $\leqslant$ & $\leqslant$ & 4.75 & Remains \\
& 0.03 & -21 & -55.0 & -3.3 & -1.15 & 0.35 & -0.65 & 0.35 & 0.0015 & 0.0015 & -5.5 & \\
\hline
\end{tabular}

\section{Characterization of micro holes}

The element composition of destination area was detected by Energy Dispersive Spectrometer (EDS, accessory of SEM, USA ). The surface morphologies of the sample were observed by scanning electron microscopy (SEM, S-3400N, Hitachi, Japan ).

\section{Results and discussion}

\section{Morphology of the micro hole, recast layer and heat affected zone}

Figure 1 is the SEM image of laser drilled hole. It reveals that the holes is about $330 \mu \mathrm{m}$ with a relatively high roundness. In order to further investigate the area near the hole surface, a magnified photo of the area is offered as is shown in Figure 1 b. It indicates that three diacritical regions (denoted as I, II and III) can be observed. The substrate (I region ), the region a little far from the hole ( II region) and the region near the hole(III region). The latter two regions are heat affected zone and recast layer, respectively, which are formed due to the percussion and heat influence of the laser.
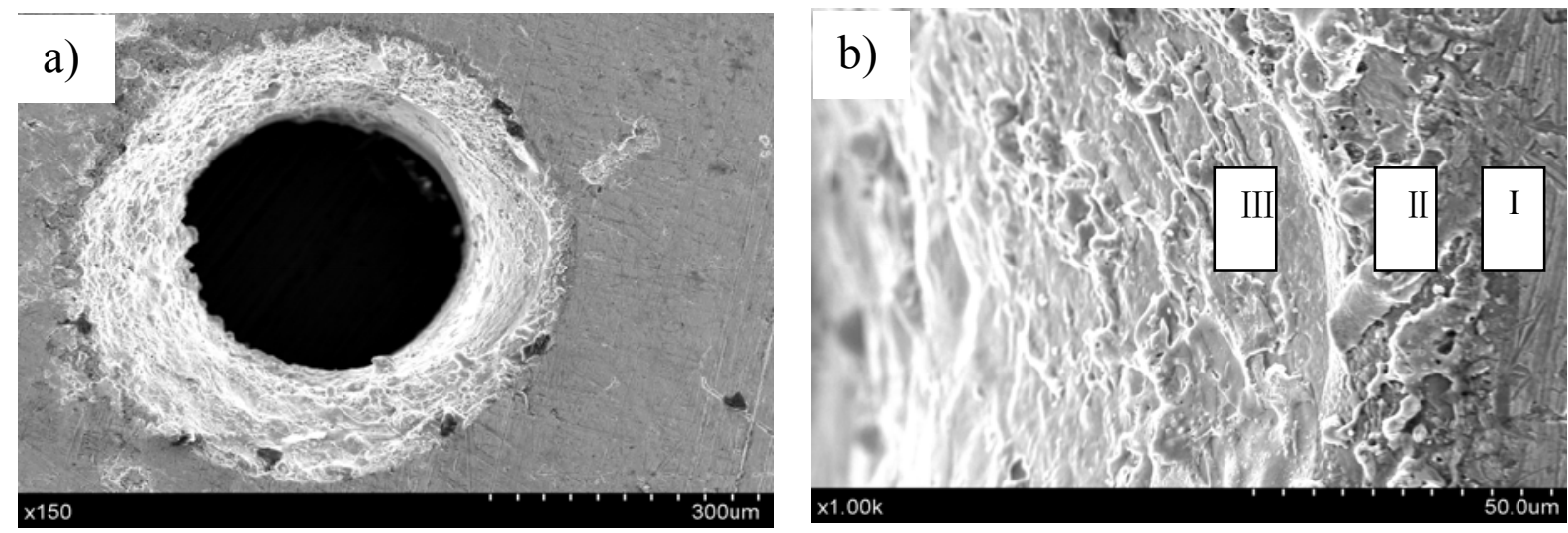

Figure 1 SEM image of laser drilled hole

\section{Elements composition}

a :little magnified photo; b: big magnified photo

Figure 2 is the SEM image and EDS image of the recast layer, heat affected zone and the substrate. It clearly shows that there is no apparent difference in the elements types, but there is some difference in the content. The most difference is the content of $\mathrm{O}$ and Fe. For heat affected zone and the recast layer, there is a increases of $\mathrm{O}$ element content and a decrease of $\mathrm{Fe}$ element content compared to that of the substrate. This is due to the auxiliary oxygen gas, which may lead to the formation of iron compound in the recast layer. And because of the thermal diffusion, the heat affected zone also shows high content of $\mathrm{O}$ element. 

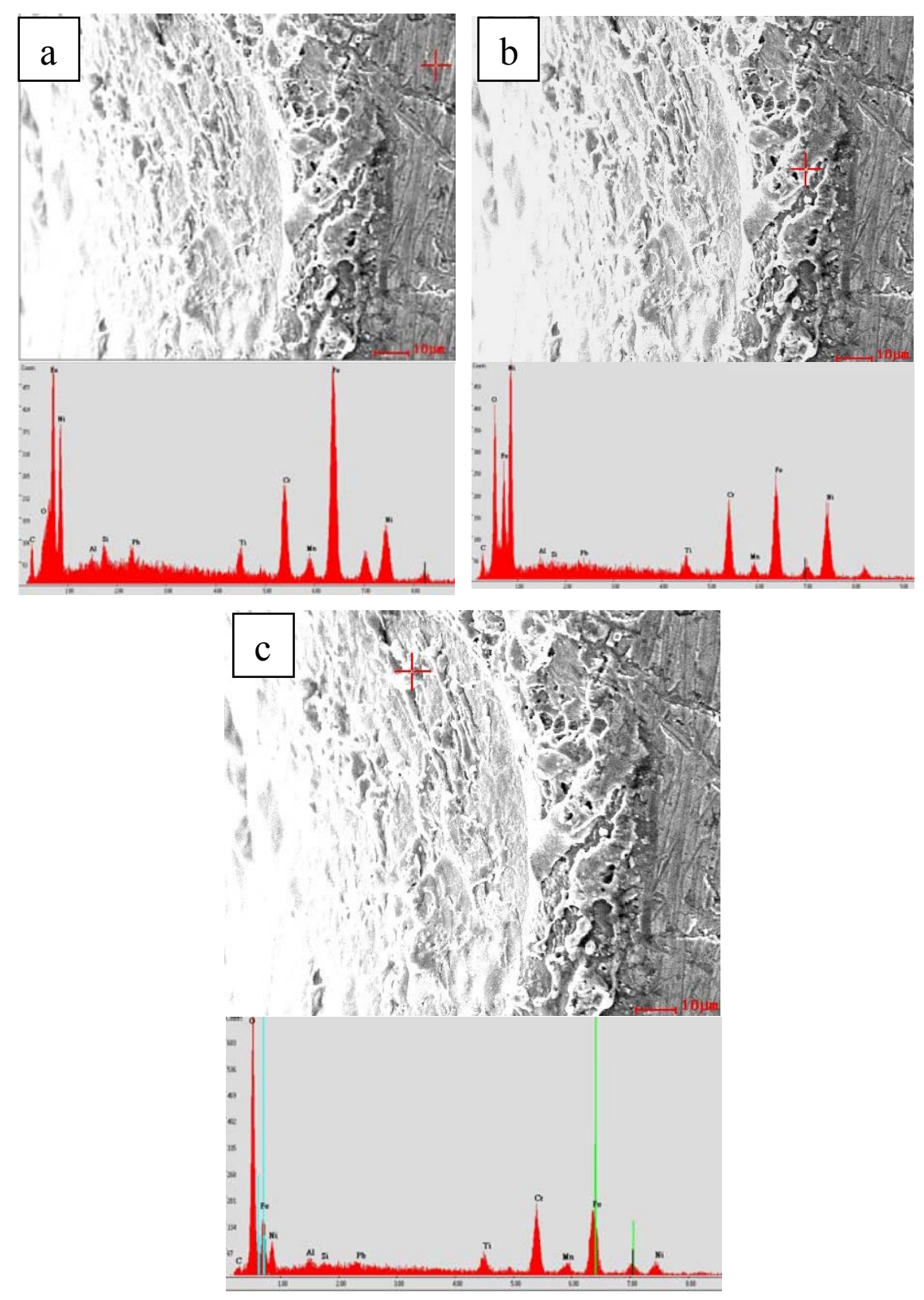

Figure 2 SEM and EDS image of hole near surface area $a$ :substrate area; $b$ : area far from the surface; c: area near the surface

\section{Conclusions}

Micro holes are formed on GH4169 super alloy using a millisecond pulse Nd:YAG laser with a average power of $65 \mathrm{~J}$ and positive defocus of $3 \mathrm{~mm}$ from the sample surface. The results indicate that the diameter of holes is about $330 \mathrm{um}$ with relatively high roundness. The elements composition of the area near the hole surface are different. It shows gradually increasing of $O$ element content and decreasing of $\mathrm{Fe}$ element content from the substrate to the area near the hole surface.

\section{Acknowledgements}

This work was supported by the Natural Science Foundation of Jiangsu Province (BK20130509), the Natural science fund for colleges and universities in Jiangsu Province (12KJB430005), the Priority Academic Program Development of Jiangsu Higher Education Institutions. The corresponding author is YunlongWang,Tel/fax:86-511-88790191,E-mail:wyl306wm@ujs.edu.cn. 


\section{References}

[1] A.H. Wang, W.Y. Wang, Z.K. Bai, C.S. Xie, D.W. Zeng and W.L. Song: YAG laser percussion drilling of a functional multi-layer thin plate. Optics \& Laser Technology Vol. 39 (2007), p. 840

[2] N.Pierron, P.Sallamand and S.Mattei: Applied Surface Science Vol. 253(2007), p3208

[3] A.Corcoran, L.Sexton, B.Seaman, P.Ryan and G.Byrne: J Mater Process Technol Vol. 123(1) (2002), p. 100

[4] S.Bandyopadhyay, J.K.Sarin Sundar, G.Sundararajan and S.V.Joshi(2002): J Mater Process Technol Vol. 127(1), p. 83

[5] S.C.Tam, C.Y.Yeo, S. Jana, Michael W.S. Lau, Lennie E.N. Lim, L.J. Yang and Yusoff Md Noor: Journal of Materials Processing Technology Vol. 37(1-4)(1993), P. 741

[6] W. Zhang, G.H. Cheng, Q.G. Feng and L.M. Cao: RARE METALS Vol. 30 (2011), p. 639

[7] X.C.Wang, H.Y.Zheng, P.L.Chu, J.L.Tan, K.M. Teh, T.Liu, C.Y.Ang.Bryden and G.H. Tay : Appl Phys A Vol. 101 (2010), p. 271

[8] Jay Tu, G.Alexander.Paleocrassas : Optics and Lasers in Engineering Vol. 55(2014), p. 275 